\title{
Parvovirus B19: Un virus ADN asociado a múltiples manifestaciones cutáneas
}

\author{
Gabriel Neely', Raúl Cabrera' y Lia Hojman'
}

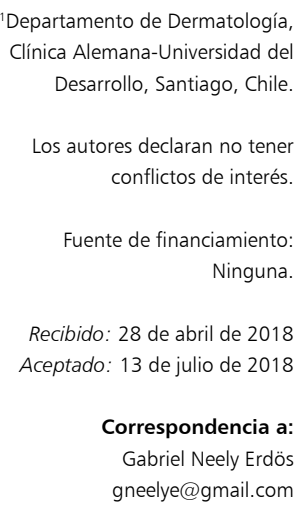

'Departamento de Dermatología, Clínica Alemana-Universidad de Desarrollo, Santiago, Chile.

Los autores declaran no tener conflictos de interés.

Fuente de financiamiento: Ninguna.

Recibido: 28 de abril de 2018 Aceptado: 13 de julio de 2018

Correspondencia a: Gabriel Neely Erdös gneelye@gmail.com

\section{Parvovirus B19: A DNA virus associated with multiple cutaneous manifestations}

Parvovirus B19 is a community DNA virus with worldwide distribution with up to $85 \%$ seroprevalence in the elderly. There is a wide spectrum of clinical manifestations in parvovirus B19 infection of which cutaneous involvement is the most frequent one. Although most of these are self-limiting conditions, there are numerous syndromes and autoimmune diseases in which parvovirus B19 is postulated as a triggering factor, given its ability to induce the production of various autoantibodies and promote the presentation of autoantigens to $\mathrm{T}$ cells. This review describes the spectrum of cutaneous manifestations of parvovirus B19 infection and the evidence supporting its association with each of them. We propose a new classification of different diseases with cutaneous manifestations linked to parvovirus B19, based on the amount and quality of available evidence in the literature.

Keywords: Exanthema; parvovirus B19; autoimmune diseases; autoimmunity; vasculitis.

Palabras clave: Exantema; parvovirus B19 enfermedades autoinmunes; autoinmunidad, vasculitis.

\section{Introducción}

$\mathrm{E}$ n la literatura médica de los últimos 30 años, la infección por parvovirus B19 (PVB19) se ha vinculado en la patogénesis de múltiples enfermedades autoinmunes. Hasta la fecha no existen estudios que hayan demostrado su rol en el desarrollo de estas enfermedades. El presente manuscrito es un trabajo de revisión de la literatura que busca relacionar diversas enfermedades con manifestaciones cutáneas, con la infección por PVB19.

\section{Material y Métodos}

Se realizó una revisión de la literatura en PubMed desde 1987 hasta 2017 de artículos en inglés, francés y español que vincularan al PVB19 como agente causal o desencadenante de diferentes enfermedades con manifestaciones cutáneas, algunas de ellas de etiología autoinmune. En un esfuerzo por reunir toda la evidencia disponible se incluyeron 113 artículos que agrupan la mayor cantidad de evidencia para cada una de las entidades clínicas estudiadas y su vínculo con este virus.

Las diferentes manifestaciones se clasificaron en típicas y atípicas según su frecuencia y el grado de asociación con la infección por PVB19. Dada la amplia variedad de enfermedades reportadas en asociación al PVB19 se propuso una subdivisión de las diferentes manifestaciones mucocutáneas atípicas según el nivel de evidencia disponible, cantidad de reportes encontrados en la literatura y comprobación serológica (IgM positivo) o virológica mediante reacción de polimerasa en cadena (RPC) para categorizar y establecer la asociación de una determinada patología con la infección por PVB19 (Tabla 2).

\section{Análisis de la literatura}

\section{El virus}

El PVB19 es un virus ADN pequeño, de hebra simple de 5.596 nucleótidos, sin manto viral, perteneciente al género Erythroparvovirus de la familia Parvoviridae ${ }^{1}$. Otros miembros de esta familia vinculados a patologías en el humano son: bocavirus 1-4, bufavirus y parvovirus $4^{1,2}$.

Actualmente se describen tres genotipos diferentes de PVB19; genotipos 1, 2 y 3, siendo el genotipo 1 el más frecuentemente descrito en el mundo. Estos diferentes genotipos presentan propiedades biológicas, patogénicas y antigénicas similares, constituyendo un único serotipo ${ }^{1,3}$. Si bien es poco frecuente, se ha reportado que más de un genotipo puede infectar a un mismo individuo ${ }^{1}$.

El genoma del PVB19 codifica para la proteína no estructural 1 (NS1) y dos proteínas estructurales de la cápside, la proteína viral (VP) 1 y $2^{4}$. La proteína NS1 varía aproximadamente $6 \%$ entre los diferentes genotipos y constituye un potente inductor de apoptosis en células permisivas al virus. El PVB19 también expresa dos proteínas no estructurales de $11 \mathrm{kDa}$ y $7 \mathrm{kDa}$ que juegan un rol en la patogenia del virus ${ }^{1}$. Por otra parte, la región única de la VP1 (VP1u) es crucial para la unión e internalización del virión en las células ${ }^{1,3}$. 


\section{Epidemiología}

La seroprevalencia del PVB19 en la población va aumentando con la edad, observándose valores aproximados de $15 \%$ en niños preescolares, $40 \%$ en adultos jóvenes y $85 \%$ en el adulto mayor ${ }^{1,5}$. En un estudio realizado en Chile, se reportó una seroprevalencia promedio de $54,8 \%$ en adultos donantes de sangre, sin diferencias entre ambos sexos ${ }^{6}$. Otro estudio nacional, demostró que en niños y adultos jóvenes la seroprevalencia varía significativamente con la edad observándose anticuerpos IgG anti-PVB19 entre 3,2 y 20,7\% en niños bajo 5 años de edad y entre 52,7 y 59,3\% en el grupo mayor de 20 años ${ }^{7}$. La variabilidad que se observó en el grupo más joven se podría explicar por los ciclos epidémicos de 3-4 años que se han descrito en la infección por PVB19. En cuanto al rol del nivel socio-económico en la prevalencia de este agente viral, existen estudios nacionales y extranjeros que muestran una mayor seroprevalencia en el grupo de nivel socio-económico bajo. Esto podría deberse al grado de hacinamiento en las condiciones de vivienda que favorecería la transmisibilidad del virus ${ }^{7,8}$.

En un estudio de 1.815 pacientes con lesiones cutáneas de diferentes patologías, se observó que en $22 \%$ de ellos existía ADN de PVB19 mediante RPC en biopsias de piel obtenidas de dichas lesiones 9 . Se ha descrito que entre 22,5 y $24 \%$ de pacientes asintomáticos presentan ADN viral de PVB19 mediante RPC en piel sana ${ }^{10}$. Lo anterior pone en duda la relevancia del hallazgo de ADN de PVB19 en biopsias de pacientes con enfermedades cutáneas, planteando la posibilidad que corresponda a una latencia post primoinfección. Por otra parte, en muestras de suero de donantes de sangre el hallazgo de ADN de PVB19 es menor, alcanzando prevalencias de hasta $1,3 \%{ }^{11}$. En Chile, un estudio mostró la presencia de ADN de PVB19 en suero en $0,84 \%$ de los donantes estudiados ${ }^{12}$.

\section{Fisiopatología de la infección viral}

El PVB19 es un patógeno comunitario frecuente en el mundo y se transmite habitualmente por vía respiratoria ${ }^{1}$. Su período de incubación dura entre 1 y 2 semanas $^{13}$. La infección también puede transmitirse verticalmente desde la madre al feto, en transfusiones sanguíneas, trasplantes de precursores hematopoyéticos y de órgano sólido.

El PVB19 se une específicamente a las células progenitoras eritroides de la médula ósea llevando a cambios estructurales que gatillan la muerte celular por apoptosis, mediada por la proteína no estructural 1 (NS1) y la proteína de $11 \mathrm{kDa}$. El antígeno $\mathrm{P}$ (globósido Gb4) es el receptor primario de la superficie celular para la infección por PVB19, encontrándose principalmente en progenitores eritroides y en otras células en menor cantidad. No todas las células que expresan el antígeno P son susceptibles, indicando que la presencia de este antígeno es necesaria pero no suficiente para que ocurra la infección ${ }^{1,4}$.

Las células objetivo de la infección por PVB19 pueden encontrarse en diferentes estadios de diferenciación, desde unidades formadoras de colonias eritroides (BFU-E) a pro-eritroblastos, incrementando proporcionalmente la susceptibilidad al virus a medida que aumenta su diferenciación. Los eritrocitos maduros, aun cuando expresan el antígeno $P$, no son permisivos a la entrada del virus, pero permiten su diseminación sistémica al mantener partículas virales unidas en su superficie. El PVB19 puede ingresar y persistir en múltiples tejidos diferentes al linaje eritroide; no obstante, no existe evidencia clara de que estas infecciones sean productivas o provoquen enfermedad ${ }^{1}$.

La respuesta inmune humoral ha sido considerada la más importante para lograr la erradicación del virus y proteger contra reinfecciones, mediante producción de IgM e IgG contra VP1/VP2. Sin embargo, existe evidencia de la presencia de ADN de PVB19 en médula ósea y suero de pacientes inmunocompetentes, aún en presencia de anticuerpos neutralizante ${ }^{14}$. Se ha sugerido que la presencia de anticuerpos IgG NS1-específicos se asocia a artritis crónica y cursos graves de la infección por PVB19 ${ }^{15-18}$. Pero otros estudios han sugerido que la presencia de estos anticuerpos no son marcadores de infección persistente ${ }^{19-21}$.

El componente celular también ha demostrado relevancia en el control de la infección aguda mediante linfocitos T CD4+ PVB19-específicos, linfocitos B que reconocen VP1 y VP2 y la producción de linfocitos T CD8+ contra NS1. Esta respuesta puede ser sostenida por meses, aún en ausencia de viremia. Por el contrario, en pacientes infectados en forma persistente por PVB19, la respuesta celular está dirigida principalmente contra VP1/VP2 más que NS1 ${ }^{1}$.

Dentro de los hallazgos que apoyan un rol del PVB19 en diferentes enfermedades autoinmunes se encuentra la producción de una gran variedad de auto-anticuerpos tras la infección, muchos de los cuales han mostrado ser claves en la patogénesis de estas entidades (e.g. anticuerpos anti-fosfolípidos, anticuerpos antinucleares y factor reumatoideo (FR). La producción de auto-anticuerpos en la infección por PVB19 probablemente se debe a mimetismo molecular, ya que anticuerpos IgG anti-PVB19 han mostrado reacciones cruzadas con múltiples auto-antígenos como: colágeno II (artritis reumatoide), queratina (lupus eritematoso sistémico), ADN de hebra simple (lupus eritematoso sistémico, artritis reumatoide (AR), miositis, hepatitis), cardiolipina, receptor de angiotensina tipo 1 , proteína básica de mielina y glicoproteína de membrana plaquetaria IIb/IIIa. También existe evidencia de apoptosis inducida por PVB19 que resulta en la presentación auto-antigénica a linfocitos $\mathrm{T}^{2}$. 


\begin{tabular}{|c|c|c|c|}
\hline Manifestaciones mucocutáneas & Frecuencia & Manifestaciones extracutáneas & Frecuencia \\
\hline Exantema & $A: 86 \% 5$ & Anemia & $A: 12 \%{ }^{23}$ \\
\hline Eritema infeccioso & $A: 76 \%^{5}$ & Compromiso articular & $\mathrm{N}: 8 \%^{112}, \mathrm{~A}: 50 \%^{27}$ \\
\hline Otros púrpuras & $A: 69 \%^{5}$ & Aborto & $5-9 \%{ }^{26}$ \\
\hline Patrón periflexural & A: $28 \%^{5}$ & & \\
\hline Vasculitis & A: $18-24 \% 5,23$ & & \\
\hline Púrpura en guante y calcetín & A: $3-10 \% \%^{5,23}$ & & \\
\hline
\end{tabular}

\section{Tabla 2. Manifestaciones mucocutáneas atípicas y su asociación con PVB19}

\section{Manifestaciones con asociación relevante*}

Lupus eritematoso sistémico

Artritis reumatoide

Vasculitis (púrpura de Schönlein-Henoch, enfermedad de Behcet, arteritis de células gigantes, Enfermedad de Kawasaki)

Esclerosis sistémica

Pityriasis lichenoides et varioliformis acuta (PLEVA)

\section{Manifestaciones con asociación posible**}

Dermatomiositis

Exantema periflexural asimétrico de la infancia

Síndrome de Wells

Síndrome de Sweet

Acrodermatitis papular de la infancia (síndrome de Gianotti-Crosti)

Crioglobulinemia y pseudo-erisipelas

Angioedema

Eritema multiforme

\section{Manifestaciones con asociación reportada***}

Manchas de Koplik

Enfermedad de Degos

Granuloma anular

Síndrome de Sjögren ${ }^{113}$

*Manifestaciones en las cuales existan 2 o más estudios de cohorte, transversales o casos y controles que apoyen la asociación con IgM y/o RPC compatible. ** Manifestaciones en las cuales existan 3 o más reportes de casos con serología IgM y/o RPC compatible. ***Manifestaciones en las cuales existan 2 o menos casos reportado con serología lgM y/o RPC compatible.

\section{Enfermedades asociadas}

Existe un amplio espectro de manifestaciones clínicas, cutáneas y sistémicas, en las infecciones por PVB19, que varían entre los diferentes grupos etarios y algunas aún son controversiales (Tabla 1). Se ha sugerido que la patogéne- sis de las erupciones cutáneas y los síntomas articulares se deben, al menos en parte, al depósito de complejos inmunes en la piel y el tejido sinovial. Esto debido a que el comienzo de las manifestaciones cutáneas y articulares coinciden con la aparición de anticuerpos específicos contra PVB19 en el suero ${ }^{1,2,22}$. Si bien existen diversos síndromes asociados a este agente, se han propuesto cuatro patrones dermatológicos en la infección primaria en adultos que en ocasiones se sobreponen: exantema maculopapular generalizado (reticulado o no reticulado), exantema en guante y calcetín, exantema periflexural y púrpura palpable 5 .

Se estima que $50 \%$ de las primo-infecciones cursan en forma asintomática y que, de los hallazgos clínicos, las lesiones cutáneas son las más frecuentes $(55 \%)^{4,23}$. Sin embargo, debe tenerse especial cuidado con los pacientes portadores de enfermedades hematológicas, inmunocomprometidos y mujeres embarazadas, puesto que pueden desarrollar complicaciones graves secundarias a la infección ${ }^{1}$.

\section{Manifestaciones cutáneas típicas}

\section{Eritema infeccioso}

También conocido como la "quinta enfermedad", nombre que adquirió de una lista de exantemas comunes de la infancia nombradas según las fechas de su primera descripción. Corresponde al hallazgo cutáneo más común en niños entre 4 y 11 años $^{24}$ y consta tradicionalmente de tres etapas: La primera se caracteriza por presentar un cuadro prodrómico leve con fiebre, coriza, cefalea y síntomas gastrointestinales. Concomitantemente ocurre una depleción de las células progenitoras eritroides, elevación de la viremia y de IgM anti-PVB19. La segunda etapa, que comienza luego de 3-7 días, se caracteriza por presentar eritema malar bilateral que respeta el puente nasal y regiones periorbitarias, conocido como el "signo de la cachetada", acompañado de palidez perioral (Figura 1). 


\section{Infectología al Día}

Característicamente, luego de la exposición solar o al calor, el exantema puede exacerbarse. Durante esta etapa ocurre una disminución de la viremia con la aparición concomitante de IgG anti-PVB19 y disminución progresiva de la contagiosidad. Luego de 1-4 días comienza la tercera etapa que consiste en la regresión del eritema malar y la aparición de un exantema maculo-papular en el tronco y extremidades. Durante su evolución se puede observar un aclaramiento central de las lesiones, dando la impresión de un patrón reticular en "encaje". Su duración generalmente varía entre 1-3 semanas; no obstante, puede durar por varios meses ${ }^{25-27}$.

Este exantema puede acompañarse de prurito y artropatía; sin embargo, no existen secuelas a largo plazo y el pronóstico es excelente. La patogenia y las manifestaciones estarían mediadas por depósito de complejos inmunes secundarios a la infección por PVB1925.

\section{Síndrome pápulo-purpúrico en guante y calcetín (SPPGC)}

Es una presentación infrecuente de la infección por PVB19 que se observa con mayor frecuencia en adultos jóvenes. Se presenta con un exantema eritematoso monomórfico, pruriginoso y doloroso, localizado en las manos y pies con límites bien definidos en muñecas y tobillos (Figura 2.1 y 2.2). Ocasionalmente se puede acompañar de fiebre y lesiones orales. Durante su evolución el exantema puede ser purpúrico, papular y petequial. Eventualmente puede presentar vesículas o bulas, seguido de descamación de palmas y plantas. A pesar de que el compromiso bien delimitado de manos y pies es el sello de este síndrome, en $50 \%$ de los casos pueden observarse lesiones en otras ubicaciones como mejillas, pliegues, codos, genitales, muslos, glúteos y rodillas ${ }^{25,26,28}$.

A diferencia del eritema infeccioso, en el cual la infectividad disminuye con la aparición del exantema, en el SPPGC el paciente es contagioso mientras está presente. El tiempo hasta su resolución es de 1-2 semanas y tiene buen pronóstico, sin secuelas a largo plazo. Este síndrome no es exclusivo de PVB19, también se ha observado en infecciones por otros agentes virales como citomegalovirus, hepatitis B, virus Epstein-Barr, virus coxsackie B6, virus herpes 6-7 y sarampión, y se han implicado fármacos como cotrimoxazol.

Se ha descrito la presencia de IgM anti-PVB19 en $70 \%$ de los pacientes con SPPGC y se ha evidenciado en múltiples estudios la existencia de ADN de PVB19 en suero y biopsias de estos pacientes, asociándolo con este agente etiológico ${ }^{28}$.

Las hipótesis actuales proponen una reacción vascular a un estímulo antigénico basado en la presencia por inmunofluorescencia directa de C3, IgM e IgA en los vasos dérmicos o debido a una reacción citotóxica contra las células infectadas por el virus ${ }^{29}$.

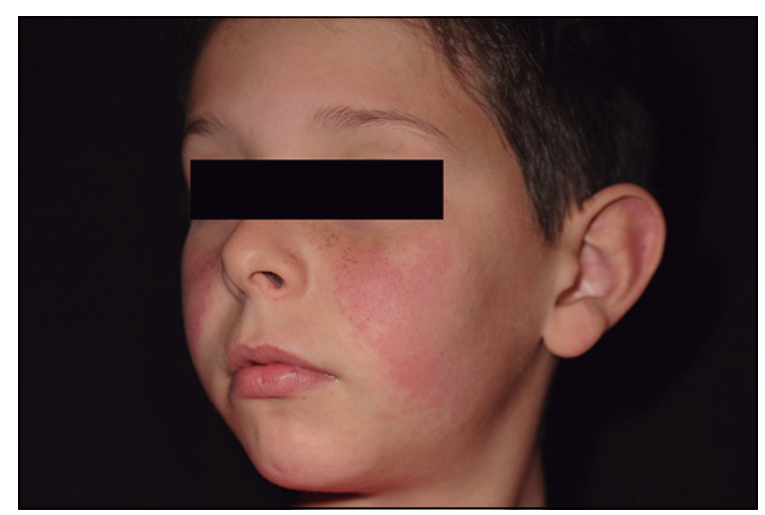

Figura 1. Paciente de 9 años con eritema infeccioso y "signo de la cachetada" con serología IgM positiva para parvovirus B19.

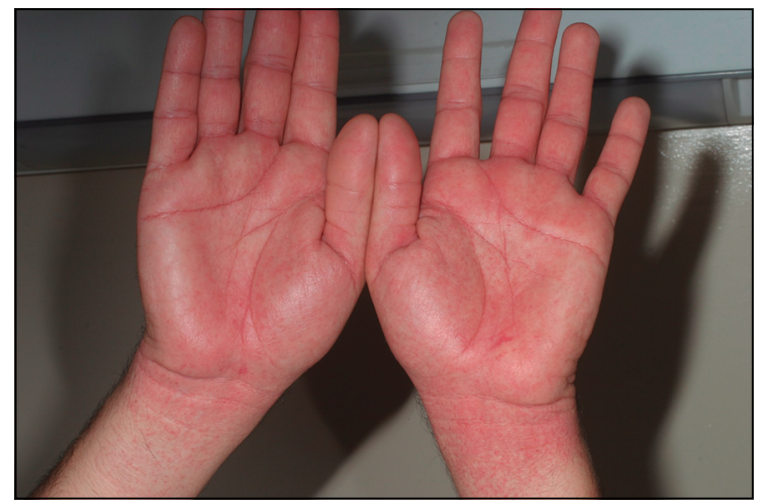

Figura 2.1. Síndrome pápulo-purpúrico en guante y calcetín: compromiso de palmas y muñecas de limites bien definidos.

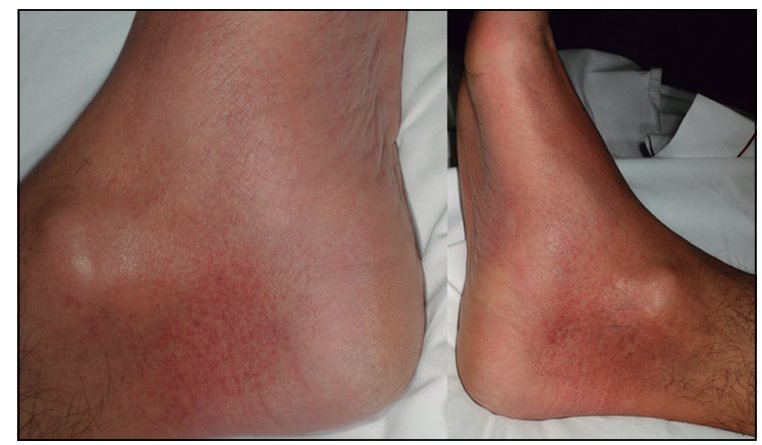

Figura 2.2. Síndrome pápulo-purpúrico en guante y calcetín: exantema papular y purpúrico de pies y plantas de límites bien definidos.

\section{Manifestaciones cutáneas atípicas}

Esta sección se presenta ordenada de acuerdo a la clasificación propuesta en la Tabla 2.

\section{Manifestaciones con asociación relevante}

\section{Lupus eritematoso sistémico (LES)}

Corresponde a una enfermedad inflamatoria multisistémica, de causa desconocida, asociada a la producción de auto-anticuerpos. Se han descrito 180 tipos de autoanticuerpos para diferentes epítopos, entre los cuales 
destacan anti-ADN doble hebra y anti-Sm por su mayor especificidad. Existe una superposición importante entre hallazgos clínicos y de laboratorio propios de la infección por PVB19 y aquellos del LES (e.g fiebre, exantema, artralgia, mialgia, linfadenopatías, anemia, citopenias, hepatitis, hipocomplementemia y producción de anticuerpos antinucleares). La infección aguda por PVB19 pueda clínicamente imitar a un LES, inducir su aparición o exacerbarlo cuando es preexistente ${ }^{2}$.

Se ha descrito el desarrollo transitorio y permanente de anticuerpos antinucleares (ANA) durante y luego de la infección por PVB19 ${ }^{30}$. Se ha propuesto que la infección por PVB19 altera el material genético original mediante la inclusión de su propio genoma en el núcleo de la célula huésped, induciendo la producción de $\mathrm{ANA}^{31}$.

En una revisión de 38 pacientes con LES asociado a infección aguda por PVB19, confirmada por IgM antiPVB19 o detección de ADN de PVB19, se describen 19 pacientes $(50 \%)$ con manifestaciones lupus-símil auto-limitadas sin LES previo. En ellos, el tiempo de resolución fue menor a tres meses en la mayoría de los casos y solamente cinco casos $(13,15 \%)$ tuvieron una duración mayor a seis meses. Se observaron seis casos $(15,78 \%)$ con LES pre-existente en quienes la infección simuló una exacerbación de su enfermedad y seis casos $(15,78 \%)$ presentaron características clínicas y de laboratorio de LES durante meses o años, apoyando la hipótesis de su inducción por PVB19. En los siete casos restantes $(18,42 \%)$ no se pudo establecer la asociación con PVB19 por ausencia de información ${ }^{32}$. En un estudio de casos y controles se comparó la seroprevalencia para PVB19 mediante ELISA para IgG en 42 pacientes con LES. Se observó una diferencia significativa con un total de 31 pacientes con LES seropositivos $(73,8 \%)$ en comparación con 21 controles $(50 \%)^{33}$.

La evidencia disponible sugiere una asociación entre el PVB19 y LES, actuando en algunos pacientes como inductor, tanto serológico como clínico. A pesar de ello, se desconocen los factores que determinan las potenciales diferentes evoluciones de esta enfermedad.

\section{Artritis reumatoide (AR)}

Es una enfermedad inflamatoria sistémica crónica, de causa desconocida, caracterizada por presentar una poliartritis simétrica de articulaciones periféricas, principalmente inter-falángicas proximales y metacarpo-falángicas. Existen múltiples auto-anticuerpos producidos por los pacientes con AR, entre los cuales el FR y el anticuerpo anti-péptidos cíclicos citrulinados (anti-CCP) son aquellos con mayor importancia en el diagnóstico y seguimiento de estos pacientes ${ }^{33}$.

Se ha sugerido un rol del PVB19 en AR por varios factores. En primer lugar, la artritis producida por la infección de este agente persiste por más de dos meses en
$20 \%$, puede ser erosiva y frecuentemente cumple criterios de AR. En segundo lugar, se ha descrito el desarrollo de FR en forma transitoria luego de infecciones agudas por PVB19 y se ha encontrado ADN viral en articulaciones afectadas en aproximadamente $75 \%$ de los pacientes con $\mathrm{AR}^{22,33}$. Un estudio japonés encontró $\mathrm{ADN}$ de PVB19 e IgM anti-PVB19 en 12 de 67 (18\%) pacientes con poliartritis inflamatoria, de los cuales, tres pacientes desarrollaron AR posteriormente con detección de FR hasta tres años después ${ }^{34}$. Sin embargo, se ha encontrado IgM anti-PVB19 en sólo 2 a $6 \%$ de los pacientes con AR durante el debut de su enfermedad y no existen diferencias de seroprevalencia de IgG anti-PVB19 entre pacientes con AR y la población general ${ }^{2}$. Se ha propuesto que un aumento de los linfocitos T reguladores CD4 y CD8 en pacientes con AR infectados con PVB19 podría llevar a una disminución de los mecanismos de eliminación viral y permitir una infección persistente en estos pacientes ${ }^{35}$.

En resumen, existe evidencia suficiente para plantear que existe una asociación entre el PVB19 y la AR. Al menos en algunos pacientes, este virus podría jugar un rol en su patogénesis ${ }^{36}$.

\section{Vasculitis}

Este término hace referencia a un grupo heterogéneo de enfermedades caracterizadas por la inflamación primaria y destrucción de los vasos sanguíneos. La presencia de antígeno $\mathrm{P}$ en el endotelio y la existencia de vasculitis en la infección fetal por PVB19 son hallazgos que sugieren un rol etiológico del PVB19 en vasculitis ${ }^{37}$. Múltiples reportes de casos han asociado la infección por PVB19 con vasculitis, específicamente púrpura de SchönleinHenoch, poliarteritis nodosa, enfermedad de Behçet, granulomatosis de Wegener, arteritis de células gigantes y enfermedad de Kawasaki ${ }^{2,22,38}$. El mecanismo fisiopatológico y su asociación aún son controversiales. Su posible rol causal estaría mediado por la formación de complejos inmunes circulantes con depósitos en la pared de vasos sanguíneos o mediante la invasión directo del epitelio por PVB19, con hallazgos morfológicos compatibles con vasculitis leucocitoclástica ${ }^{37}$.

En el púrpura de Schönlein-Henoch (PSH) del adulto se ha reportado la presencia de ADN de PVB19 en capilares dérmicos y glomerulares ${ }^{39}$. Además, la elevación de IgM anti-PVB19 en forma simultánea con el comienzo del PSH ha propuesto una asociación ${ }^{40}$.

Se ha evaluado la presencia de IgM anti-PVB19 en pacientes con $\mathrm{PSH}$, encontrándose únicamente en 10$11 \%$ de los casos, sin diferencias significativas con los controles $^{41,42}$. De existir asociación, ésta jugaría un papel marginal.

Existen pocos casos reportados de poliarteritis nodosa (PAN) con pruebas serológicas positivas y/o presencia de ADN de PVB19 en suero o tejido ${ }^{43-45}$. En un estudio 
se evaluaron las biopsias de múltiples órganos de 10 pacientes con PAN y siete con poliangeítis microscópica (MPA) de los cuales ninguno presentaba ADN de PVB19 mediante RPC ${ }^{46}$.

En la enfermedad de Behçet (EB) se han reportado asociaciones serológicas con PVB19, aunque sin hallazgos concluyentes ${ }^{47}$. Un estudio de casos y controles que incluyó 55 pacientes con EB determinó que la prevalencia de IgG e IgM anti-PVB19, así como la presencia de ADN de PVB19 en el suero, era similar en ambos grupos ${ }^{48}$.

En un estudio de casos y controles se realizó RPC cuantitativa para ADN de PVB19 en lesiones de piel de 40 pacientes con EB, observándose una cantidad significativamente mayor de $\mathrm{ADN}$ en el grupo con $\mathrm{EB}$, especialmente en las lesiones no ulceradas. Esto último puede deberse a una menor cantidad de partículas virales en las lesiones ulceradas por la pérdida epitelial o a diferentes estímulos antigénicos entre las lesiones de la EB. En consecuencia, se puede plantear que la respuesta inmune contra el PVB19 sería responsable de las lesiones no ulceradas en esta enfermedad ${ }^{49}$.

Se han reportado algunos pacientes con granulomatosis de Wegener (GW) con anticuerpos IgM anti-PVB19 positivos y/o presencia de ADN de PVB19 en suero ${ }^{50,51}$. Un estudio de casos y controles incluyó 13 adultos con vasculitis positivas para anticuerpos anticitoplasma de neutrófilos (ANCA), entre ellos seis pacientes con GW. En estos pacientes la seroprevalencia fue similar a los controles y no fue posible encontrar ADN de PVB19 en suero. Estos hallazgos ponen en duda un rol etiológico de PVB19 en la GW52.

En la arteritis de células gigantes (ACG) existe evidencia contrapuesta. De los únicos tres estudios de casos y controles publicados en la literatura médica ${ }^{53-55}$, solamente uno encontró una asociación positiva mediante RPC cuantitativa para ADN de PVB19 en biopsias de arteria temporal, especialmente en aquellos con cargas virales mayores $^{54}$. Un estudio prospectivo examinó las biopsias de arteria temporal de 50 pacientes y detectó ADN de PVB19 mediante RPC en siete de 13 muestras (54\%) con evidencia histológica de ACG. Esto se observó solamente en cuatro de $37(\sim 11 \%)$ muestras negativas para $\mathrm{ACG}^{56}$.

Para evaluar el rol del PVB19 en la enfermedad de Kawasaki (EK), un estudio comparó el suero de 15 pacientes con EK, 21 pacientes con otros exantemas virales y 15 controles sanos en búsqueda de ADN de PVB19, IgM e IgG anti-PVB19. Se observó ADN de PVB19 en 9 pacientes $(60 \%)$ con $\mathrm{EK}$, de los cuales sólo cuatro presentaron IgM anti-PVB19. Ninguno de los controles o pacientes con otros exantemas virales presentó IgM o ADN de PVB1957. Otro estudio descartó la presencia de ADN de PVB19 en células endoteliales circulantes de 18 pacientes con lesiones en arterias coronarias secundario a la EK, sugiriendo que la infección endotelial por PVB19 no estaría involucrado en el compromiso coronario de estos pacientes ${ }^{58}$.

De todas las vasculitis en las que se ha propuesto una asociación con PVB19, únicamente el PSH, la EB, la ACG y la EK podrían estar relacionadas al PVB19 en su patogenia. En la PAN y GW la evidencia es inconsistente, poniéndose en duda su real asociación con PVB19.

\section{Esclerosis sistémica (ES)}

Es una enfermedad del tejido conectivo multisistémica que afecta la piel, tracto gastrointestinal, corazón, pulmones, riñones y sistema nervioso periférico ${ }^{2}$. En un estudio de 29 pacientes con ES, se ha vinculado con la infección por PVB19 dada la presencia de ADN de PVB19 en médula ósea en $59 \%$ de los casos ( 17 casos), pero en ninguno de los controles. Además, se encontró ADN de PVB19 en la piel de 39 pacientes con ES (80\%), siendo el genotipo 1 el más frecuentemente encontrado. La persistencia simultánea de genotipos 1 y 2 se observó en biopsias de piel de 10 pacientes $(20 \%)$ y en médula ósea de 9 pacientes (31\%); sin embargo, esto no se observó en los controles ${ }^{59}$.

En otro estudio se incluyó a 21 pacientes con ES y se observó IgG anti-NS1 de PVB19 en siete casos (33\%) resultando mayor que en los controles $(13 \%)^{60}$. En relación al mecanismo fisiopatológico, se determinó en un grupo de 12 pacientes con ES (limitada y difusa) la presencia de ADN de PVB19 en células endoteliales y fibroblastos, con un aumento en la expresión de TNF-alfa y depósitos vasculares de complemento (C5b-9). Estos hallazgos - presentes aun en ausencia de viremia- sugieren un rol de la inmunidad humoral contra la injuria viral provocada por PVB19 en la patogénesis de la $\mathrm{ES}^{61}$.

\section{Pitiriasis liquenoide (PL)}

Corresponde a una dermatosis inflamatoria infrecuente, de etiología desconocida y con tendencia auto-involutiva. Actualmente se puede dividir en pityriasis lichenoides et varioliformis acuta (PLEVA), pitiriasis liquenoide crónica (PLC) y una variante úlcero-necrótica febril ${ }^{62}$. Se ha reportado la presencia de ADN de PVB19 en muestras de piel lesional en nueve pacientes $(30 \%)$ con PLEVA de un total de 30 con diferentes formas de PL, sugiriendo una asociación del PVB19 específicamente con PLEVA. La estrecha proximidad de linfocitos T citotóxicos a queratinocitos epidérmicos en los pacientes con PL sugiere una reacción contra antígenos epidérmicos. Es probable que la infección por PVB19 provoque cambios antigénicos del queratinocito que gatillen esta reacción ${ }^{63}$.

Otro estudio incluyó 10 pacientes con PLEVA y 17 controles con papulosis linfomatoide para estudio de RPC para ADN de PVB19 en piel lesional. Se identificó PVB19 en tres $(30 \%)$ pacientes con PLEVA; sin embargo, no se pudo detectar en los controles alguno ${ }^{64}$. 
Se ha publicado el caso de un paciente de 12 años que presentó un cuadro compatible, clínica e histológicamente, con la variante úlcero-necrótica febril de PL. El estudio de laboratorio reveló la presencia de IgM, IgG y ADN de PVB19 en el suero del paciente; sin embargo, la RPC para ADN de PVB19 fue negativa en los hisopados de piel y faringe ${ }^{65}$.

\section{Manifestaciones con asociación posible}

\section{Dermatomiositis (DM)}

Enfermedad autoinmune sistémica caracterizada por inflamación cutánea y muscular crónica de causa desconocida. Las manifestaciones clínicas típicas son debilidad muscular proximal, eritema violáceo característico periocular (eritema heliotropo) y la presencia de placas descamativa en los nudillos (pápulas de Gottron). En las últimas décadas se ha descrito en su patogénesis una injuria microvascular inmuno-mediada por la presencia de depósitos de complemento (C5b-9) en vasos cutáneos, pulmonares y musculares. Se han reportado cinco casos de DM adulta y juvenil con presencia de ADN de PVB19 en piel o músculo o IgM positiva anti-PVB19 en suero ${ }^{66,67}$. Sin embargo, en un estudio de casos y controles de 62 pacientes con DM juvenil, en el que se evaluó mediante serología y RPC de suero y tejido muscular, no se encontró asociación positiva entre el inicio de la patología y la infección por PVB19. Además, la seroprevalencia en los casos de DM juvenil fue similar a la reportada en pacientes sanos ${ }^{68}$. Estos datos sugieren que las asociaciones

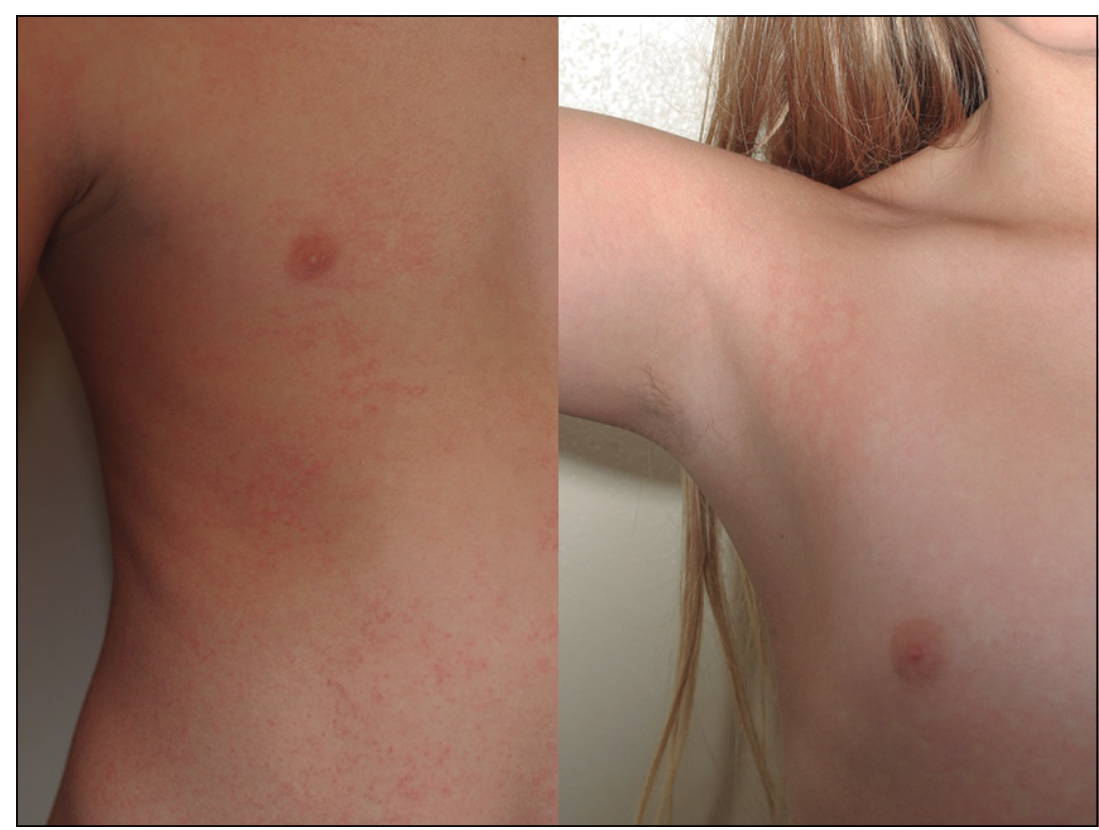

Figura 3. Exantema periflexural asimétrico con extensión a tórax y brazo ipsilateral en dos pacientes con serología IgM positiva para parvovirus B19. anteriores entre la infección por PVB19 y el desarrollo de DM aún no son claras.

\section{Exantema periflexural asimétrico de la infancia}

También conocido como exantema latero-torácico unilateral de la infancia, corresponde a una erupción maculopapular escarlatiniforme, más frecuente en niños, ubicándose característicamente en el pliegue axilar con extensión centrífuga hacia el tórax y la porción proximal del brazo ipsilateral (Figura 3). En ocasiones puede haber prurito moderado, adenopatías locales (en la mitad de los pacientes) y compromiso contralateral, aunque de menor extensión. También se ha descrito casos con inicio en pliegue inguinal, antecubital y poplíteo ${ }^{69,70}$.

Se han reportado tres casos ${ }^{70,71}$ asociados a infección por PVB19, uno de ellos adulto. Todos presentaban IgM positiva e IgG negativa para PVB19, indicando infección reciente. Las serologías para otros agentes resultaron negativas. La biopsia cutánea de uno de ellos reveló una dermatitis de interfase leve a moderada con infiltrado linfocitario y predominio alrededor de las glándulas sudoríparas $^{70}$.

A pesar de que el curso de la enfermedad y las características de los pacientes sugieren un desorden infeccioso, hasta la fecha no se ha podido identificar un agente causal con claridad ${ }^{72-74}$. Por lo tanto, es probable que este cuadro corresponda a un patrón de reacción contra diferentes agentes virales.

\section{Sindrome de Wells}

Este cuadro también conocido como celulitis eosinofílica, se caracteriza por la aparición de placas eritematosas, grises o violáceas, simulando una celulitis bacteriana, aunque sus manifestaciones son heterogéneas. La etiología aún es desconocida ${ }^{75}$.

Se han reportado cuatro casos ${ }^{76-79}$ de S. de Wells asociado a infección por PVB19, de los cuales sólo uno presenta IgM y RPC (tanto sérica como en piel lesional) positivas para este virus. Lo anterior refuerza la hipótesis de que el $\mathrm{S}$. de Wells corresponde a un patrón de reacción común a diferentes gatillantes, entre los cuales se encuentra la infección por PVB $19^{75}$. Si bien este síndrome es más frecuente en adultos que en niños, todos los casos asociados a PVB19 descritos han ocurrido en niños menores de 8 años.

\section{Sindrome de Sweet (SS)}

También conocido como dermatosis neutrofílica febril, corresponde a una dermatosis neutrofílica caracterizada por fiebre y aparición de pápulas, nódulos y placas eritematosas dolorosas. Se ha sugerido que corresponde a una reacción de hipersensibilidad inusual secundaria a infecciones, enfermedades autoinmunes, neoplasias y fármacos, mediada por citoquinas probablemente activadas por IL- $1^{80}$. 
Se han reportado cinco $\operatorname{casos}^{67,81,82}$ de pacientes con lesiones similares a las del SS y evidencia de infección por PVB19, de los cuales solamente dos ${ }^{67}$ tienen IgM y RPC de piel lesional positivas para PVB19.

\section{Acrodermatitis papular de la infancia (Síndrome de Gianotti-Crosti)}

Corresponde a una acrodermatitis papulo-vesicular autolimitada de distribución simétrica. Se ha asociada a infecciones virales, bacterianas e inmunizaciones, principalmente en niños. Los casos originales descritos por Gianotti en 1955 estaban asociados a infección por virus hepatitis B, pero se han descrito casos asociados a virus Epstein-Barr, virus Coxsackie A, virus parainfluenza 1 y 2, Poxvirus, entre otros ${ }^{83-85}$.

Se han reportado cuatro casos asociados a infección por PVB19 ${ }^{83-86}$. Uno de ellos es un adulto y coinfectado con virus Epstein-Barr. En consecuencia, es posible que este síndrome represente un patrón de reacción inespecífico ante diversos estímulos, uno de ellos el PVB19, similar a lo observado en el exantema periflexural asimétrico de la infancia.

\section{Crioglobulinemia y pseudo-erisipelas}

La crioglobulinemia se define como la presencia de inmunoglobulinas circulantes que precipitan con bajas temperaturas y que se disuelven al aumentarla. La mayoría de las crioglobulinemias mixtas tipo II están asociadas a la infección crónica por virus de hepatitis C (VHC) (70$90 \%$ ) y pueden ser responsables de vasculitis sistémicas llamadas vasculitis crioglobulinémicas ${ }^{87}$. Si bien el rol de PVB19 en la crioglobulinemia es controversial, un estudio francés (CryoVas survey) reportó, entre 18 pacientes con vasculitis crioglobulinémica no asociadas a VHC, un caso (5\%) asociado a infección por PVB19 ${ }^{88}$.

Se han reportado cuatro casos ${ }^{87,89-91}$ de crioglobulinemia tipo II (IgM monoclonal) asociada a infección por PVB19, todos ellos con IgM y RPC sérica positiva para PVB19. Se encontró ADN viral de PVB19 en el crioprecipitado mediante RPC y factor reumatoideo en tres de ellos. Dos casos se presentaron con púrpura y uno presentó placas eritematosas y edematosas bien definidas en ambas extremidades inferiores, similares a erisipela ${ }^{91}$.

Por lo tanto, la infección por PVB19 constituye un agente causal de vasculitis crioglobulinémica no asociada a VHC y debe tenerse en cuenta en el estudio etiológico de una vasculitis.

\section{Angioedema}

Se han reportado tres casos de angioedema con evidencia de infección aguda por PVB19 mediante anticuerpos $\operatorname{IgM}$ e IgG asociados a poliartralgias y poliartritis ${ }^{92}$, uno de ellos con deficiencia transitoria de inhibidor de $\mathrm{C} 1$ esterasa (C1-INH) y otro asociado a hipocomplementemia transitoria con niveles disminuidos de $\mathrm{C} 4$.

Además, se ha reportado un caso de angioedema en un neonato luego de una infección intrauterina a las 22 semanas por PVB19 asociado a historia de hidrops y sufrimiento fetal. Únicamente los anticuerpos IgG anti-PVB19 resultaron positivos en sangre del cordón umbilical. Se observaron niveles disminuidos de C1-INH y de la actividad total del complemento (CH50), con niveles normales de otros componentes del complemento (C1q, C3, C4). Luego de dos semanas, los niveles de C1-INH y CH50 aumentaron considerablemente hasta alcanzar niveles de adulto y la IgG anti-PVB19 persistió elevada en la sangre del lactante hasta seis meses después ${ }^{93}$.

Si bien la fisiopatología de los episodios de angioedema en la infección por PVB19 aún no es clara, es importante conocer su existencia. Se debe considerar especialmente en neonatos, en quienes el edema laríngeo es significativamente riesgoso por la estrechez de su vía aérea.

\section{Eritema multiforme}

Constituye una enfermedad cutánea aguda, autolimitada y recurrente, caracterizada por lesiones papulares tipo diana y asociada a infecciones en $90 \%$, de las cuales, $70 \%$ se deben a infección por virus herpes simplex ${ }^{94,95}$.

Se han reportado tres $\operatorname{casos}^{96-98}$ de eritema multiforme asociado a infección aguda por PVB19, dos de ellos de subtipo buloso. Si bien es poco frecuente, el PVB19 debe considerarse por su posible asociación con eritema multiforme junto a otros agentes como el virus varicela-zoster, citomegalovirus y Mycoplasma pneumoniae ${ }^{95}$.

\section{Manifestaciones con asociación reportada}

\section{Manchas de Koplik}

Corresponde a un signo clínico considerado inicialmente como patognomónico de sarampión y observado en más de $70 \%$ de los pacientes. Fueron descritas como puntos o manchas blanco-grisáceas en un fondo rojo al interior de la mejilla ${ }^{99}$. Basado en la clasificación actual, pueden clasificarse como pápulas blanco-grisáceas en la mucosa oral ${ }^{100}$. Posteriormente se ha reportado como manifestación anecdótica en infecciones por echovirus-9 y PVB19101-103.

Existen solamente dos casos reportados en la literatura médica de manchas de Koplik en la mucosa oral en infección por PVB19. El primero ocurrió al sexto día en una paciente de 26 años con erupción purpúrica sin vasculitis. En este caso las manchas de Koplik se ubicaban en la encía anteroinferior además de su sitio clásico en la mucosa oral posterior bilateral ${ }^{102}$. El segundo caso ocurrió en una paciente de 35 años cursando un embarazo de 12 semanas, asociado a pseudo-celulitis de las nalgas, vulva 
y enantema de la mucosa oral con ulceraciones. En este caso, las manchas de Koplik presentaban una distribución clásica $^{103}$. Ambas pacientes presentaban fiebre, anemia y artralgias, además de IgM positiva e IgG negativa para PVB19, compatible con infección aguda. Las serologías de otros agentes, incluyendo sarampión, resultaron negativas o con evidencia de inmunidad pasada ${ }^{102,103}$.

Si bien es una manifestación mucosa extremadamente infrecuente de la infección por PVB19, es importante por su diagnóstico diferencial con sarampión y las implicancias de pronóstico que conlleva.

\section{Enfermedad de Degos}

La enfermedad de Degos (ED), también llamada papulosis atrófica maligna es una vasculopatía multiorgánica de vasos de pequeño y mediano calibre, caracterizada por infartos limitados en el sistema nervioso central, gastrointestinal y cutáneos de etiología desconocida. Ha sido reportada una variante exclusivamente cutánea y de curso benigno. Esta enfermedad ha sido asociada con dermatomiositis, esclerodermia, LES y síndrome de anticuerpo antifosfolípido. El hallazgo cutáneo es patognomónico y consiste en pápulas de centro atrófico color blanco-porcelana y un borde violáceo periférico con telangiectasias, principalmente en el tronco y las extremidades superiores ${ }^{104}$. Se han reportado solamente dos casos ${ }^{105,106}$ en la literatura médica, asociados a infecciones por PVB19 demostrado mediante la presencia de ARN de PVB19 por RPC con transcriptasa inversa in situ en lesiones de piel con manifestaciones similares a ED; sin embargo, ninguno de ellos presentaba evidencia serológica de infección aguda. En ambos casos se observaron depósitos de C5b-9 en los vasos sanguíneos dérmicos mediante inmunofluorescencia, posiblemente contribuyendo a la injuria endotelial.

\section{Granuloma anular}

Corresponde a una dermatosis benigna, inflamatoria y granulomatosa de etiología desconocida. Generalmente se presenta como placas anulares o arciformes auto-limitadas de color rosado o violáceo en las extremidades de personas jóvenes. Se han descrito dos $\operatorname{casos}^{66,67}$ de pacientes que desarrollaron lesiones compatibles (clínica e histológicamente) con granuloma anular posterior a la exposición con pacientes con eritema infeccioso, en los cuales sólo se evidenció ADN de PVB19 en las biopsias de dichas lesiones. La ausencia de serología en estos pacientes no permite diferenciar si estos hallazgos corresponden a una infección aguda o una portación de este agente.

\section{Conclusión}

Las diversas manifestaciones cutáneas de la infección por PVB19 deben ser consideradas en la práctica diaria, tanto por su diversidad como por la potencial gravedad de algunas de ellas. Sin embargo, la evidencia reciente de la portación inocente de este agente en pacientes sanos dificulta su asociación con algunas manifestaciones dermatológicas.

La asociación de un agente determinado con una enfermedad ha sido motivo de discusión, especialmente desde el siglo XIX, luego de que Louis Pasteur propusiera la "teoría germinal de las enfermedades". En el año 1890 Robert Koch publica sus postulados para establecer una relación causal entre un microorganismo y una enfermedad; sin embargo, con los avances en biología molecular su aplicabilidad se ha reducido. En consecuencia, Fredricks y Relman han propuesto criterios de asociación que consideran métodos de identificación microbiana basados en su secuencia genómica ${ }^{107}$.

Se debe considerar que estos criterios, al igual que los postulados de Koch, no son absolutos y no se requiere la presencia de todos para establecer la relación causal entre un agente y una enfermedad. Sin embargo, la capacidad de cumplir alguno o todos estos criterios otorga mayor evidencia de una relación clínicamente importante entre el hospedero y el agente ${ }^{107}$.

En el caso del PVB19 y las diferentes manifestaciones expuestas en esta revisión, varios de estos criterios se cumplen consistentemente para algunas enfermedades y el virus juega un rol pivotal en su inducción (ej.: eritema infeccioso, SPPGC, AR, LES). En otros casos, la evidencia de asociación entre esta infección viral y una enfermedad es escasa (ej.: poliarteritis nodosa y granulomatosis de Wegener) y se requieren mayores estudios.

En la presente revisión se muestran las diferentes enfermedades con manifestaciones cutáneas que han sido reportadas, en mayor o menor medida, en asociación a la infección por PVB19. Para cada una de ellas se resume gran parte de la evidencia disponible con el fin de agrupar y clasificar estas enfermedades según el grado de asociación que existe con la infección por este agente en particular.

La amplia gama de manifestaciones cutáneas y no cutáneas relacionadas a la infección por PVB19 podrían explicarse en parte por su afinidad por células hematopoyéticas y su capacidad de inducir la producción de auto-anticuerpos mediante mimetismo molecular. Otro aspecto a considerar es la existencia de correceptores diferentes al antígeno P para el PVB19: Ku80 e integrina $\alpha 5 \beta 1^{108,109}$. La expresión de Ku80 en la superficie de células inmunes en la médula ósea y la detección de PVB19 en las mismas, podría explicar y apoyar la asociación de este agente con diferentes enfermedades autoinmunes, teniendo en cuenta que, tanto la inmunidad humoral como la inmunidad celular son relevantes y capaces de modular el curso de la infección ${ }^{108}$. Esto demuestra que aún existen áreas de la patogenia que no conocemos y que 


\section{Infectología al Día}

posiblemente una vez reconocidas, puedan explicar por qué un mismo microorganismo puede dar tantas formas clínicas de enfermedad.

Si bien se han desarrollado vacunas recombinantes para PVB19 con producción de anticuerpos neutralizantes ${ }^{110}$, uno de los ensayos clínicos más recientes fue interrumpido por el desarrollo de exantemas ${ }^{111}$.

Es fundamental que el clínico conozca las múltiples manifestaciones cutáneas de la infección por PVB19 con el fin de considerarlo como agente etiológico en el diagnóstico diferencial de los cuadros expuestos y de esta manera, aumentar la evidencia sobre el rol que pudiera jugar en las diferentes patologías.

Agradecimientos: A Mauricio Urrutia y Andrea Zalavari por su ayuda en la preparación del material fotográfico. A Ximena Fajre por su colaboración y disposición en el proceso de revisión.

\section{Resumen}

El parvovirus B19 es un virus ADN comunitario distribuido a nivel mundial con seroprevalencias que alcanzan hasta $85 \%$ en el adulto mayor. Existe un amplio espectro de manifestaciones clínicas en la infección por parvovirus B19 siendo las cutáneas las más frecuentes. Si bien, la mayoría de éstas son autolimitadas, existen numerosos síndromes y enfermedades autoinmunes en los cuales se postula al parvovirus B19 como factor gatillante, dada su capacidad de inducir la producción de numerosos autoanticuerpos y promover la presentación de autoantígenos a linfocitos T. En la presente revisión se describe el espectro de manifestaciones cutáneas de la infección por parvovirus B19 y la evidencia que apoya su asociación con cada una de ellas. Se propone una clasificación de las diferentes enfermedades con manifestaciones cutáneas vinculadas al parvovirus B19, basado en la cantidad y calidad de la evidencia disponible en la literatura científica.

\section{Referencias bibliográficas}

1.- Qiu J, Söderlund-Venermo M, Young NS. Human parvoviruses. Clin Microbiol Rev. 2017; 30 (1): 43-113. DOI:10.1128/ CMR.00040-16.

2.- Kerr J R. The role of parvovirus B19 in the pathogenesis of autoimmunity and autoimmune disease. J Clin Pathol 2016; 69 (4): 279-91. DOI:10.1136/jclinpath-2015-203455.

3.- Servant-Delmas A, Morinet F. Update of the human parvovirus B19 biology. Transfus Clin Biol 2016; 23 (1): 5-12. DOI:10.1016/j. tracli.2015.11.006

4.- Landry M L. Parvovirus B19. Microbiol Spectr 2016; 4 (3): 297-310. DOI:10.1128/ microbiolspec.DMIH2-0008-2015.

5.- Mage V, Lipsker D, Barbarot S, Bessis D, Chosidow O, Del Giudice P, et al. Different patterns of skin manifestations associated with parvovirus B19 primary infection in adults. J Am Acad Dermatol 2014; 71 (1): 62-9. DOI:10.1016/j.jaad.2014.02.044.

6.- Gaggero A, Rivera J, Calquín E, Larrañaga C E, León O, Díaz P, et al. Seroprevalencia de anticuerpos IgG contra parvovirus B19 en donantes de sangre de hospitales en Santiago, Chile. Rev Med Chile 2007; 135 (4): 443-8. DOI:10.4067/S003498872007000400005 .

7.- Abarca K, Cohen B J, Vial P A. Seroprevalence of parvovirus B19 in urban Chilean children and young adults, 1990 and 1996. Epidemiol Infect 2002; 128: 59-62. DOI:10.1017/ S0950268801006203.

8.- de Freitas R B, Wong D, Boswell F, de Miranda M F, Linhares A C, Shirley J, et al.
Prevalence of human parvovirus (B19) and rubella virus infections in urban and remote rural areas in northern Brazil. J Med Virol 1990; 32 (4): 203-8.

9.- Santonja C, Santos-Briz A, Palmedo G, Kutzner $\mathrm{H}$, Requena L. Detection of human parvovirus B19 DNA in 22\% of 1815 cutaneous biopsies of a wide variety of dermatological conditions suggests viral persistence after primary infection and casts doubts on its pathogenic significance. Br J Dermatol 2017; 38 (1): 42-9. DOI:10.1111/bjd.15382.

10.- Bonvicini F, La Placa M, Manaresi E, Gallinella G, Gentilomi GA, Zerbini M, et al. Parvovirus B19 DNA is commonly harboured in human skin. Dermatology 2010; 220 (2): 138-42. DOI:10.1159/000277431.

11.- Candotti D, Etiz N, Parsyan A, Allain J-P. Identification and characterization of persistent human erythrovirus infection in blood donor samples. J Virol 2004; 78 (22): 12169-78. DOI:10.1128/JVI.78.22.12169-12178.2004.

12.- Lévican J, Torres M, Gaggero N, Corvalán R, Gaggero A. Parvovirus B19 among blood donors from three hospitals in Santiago, Chile. Rev Med Chile 2011; 139 (2): 143-9. DOI:/ S0034-98872011000200001.

13.- Martínez G M J, Elgueta N A. Manifestaciones purpúricas atípicas por parvovirus B19 en dos miembros de una familia: Caso clínico. Rev Med Chile 2008; 136(5): 620-3. DOI:10.4067/ S0034-98872008000500011.

14.- Aravindh R, Saikia U N, Mishra B, Kumari V, Sarkar S, Sharma M, et al. Persistence of human parvovirus B19 in tissues from adult individuals: a comparison with serostatus and its clinical utility. Arch Virol 2014; 159 (9):
2371-6. DOI:10.1007/s00705-014-2065-8.

15.- von Poblotzki A, Gigler A, Lang B, Wolf H, Modrow S. Antibodies to parvovirus B19 NS-1 protein in infected individuals. J Gen Virol 1995;76 ( Pt 3): 519-27. DOI:10.1099/00221317-76-3-519.

16.- von Poblotzki A, Hemauer A, Gigler A, Puchhammer-Stöckl E, Heinz F X, Pont J, et al. Antibodies to the nonstructural protein of parvovirus B19 in persistently infected patients: implications for pathogenesis. J Infect Dis 1995; 172 (5): 1356-9.

17.- Hemauer A, Gigler A, Searle K, Beckenlehner K, Raab U, Broliden K, et al. Seroprevalence of parvovirus B19 NS1-specific IgG in B19infected and uninfected individuals and in infected pregnant women. J Med Virol 2000; 60 (1): 48-55.

18.- Tzang B-S, Tsai C-C, Tsay GJ, Wang M, Sun Y-S, Hsu T-C. Anti-human parvovirus B19 nonstructural protein antibodies in patients with rheumatoid arthritis. Clin Chim Acta 2009; 405 (1-2): 76-82. DOI:10.1016/j.cca.2009.04.002.

19.- Searle K, Schalasta G, Enders G. Development of antibodies to the nonstructural protein NS1 of parvovirus B19 during acute symptomatic and subclinical infection in pregnancy: implications for pathogenesis doubtful. J Med Virol 1998; 56 (3): 192-8.

20.- Venturoli S, Gallinella G, Manaresi E, Gentilomi G, Musiani M, Zerbini M. IgG response to the immunoreactive region of parvovirus B19 nonstructural protein by immunoblot assay with a recombinant antigen. J Infect Dis 1998; 178 (6):1826-9.

21.- Jones L P, Erdman D D, Anderson L J. Prevalence of antibodies to human parvovirus 
B19 nonstructural protein in persons with various clinical outcomes following B19 infection. J Infect Dis 1999; 180 (2): 500-4. DOI:10.1086/314894.

22.- Page C, François C, Goëb V, Duverlie G. Human parvovirus B19 and autoimmune diseases. Review of the literature and pathophysiological hypotheses. J Clin Virol 2015; 72: 69-74. DOI:10.1016/j. jcv.2015.09.007.

23.- Rodríguez Bandera A I, Mayor Arenal M, Vorlicka K, Ruiz Bravo-Burguilllos E, Montero Vega D, Vidaurrázaga DíazArcaya C. Acute parvovirus B19 infection in adults: a retrospective study of 49 cases. Actas Dermosifiliogr 2015; 106 (1):4 4-50. DOI:10.1016/j.ad.2014.06.004.

24.- Exindari M, Chatzidimitriou D, Melidou A, Gioula G, Ziogou L, Diza E. Epidemiological and clinical characteristics of human parvovirus B19 infections during 2006-2009 in Northern Greece. Hippokratia 2011; 15 (2): 157-60.

25.- Valentin M N, Cohen P J. Pediatric parvovirus B19: spectrum of clinical manifestations. Cutis 2013; 92 (4): 179-84.

26.- Young N S, Brown K E. Parvovirus B19. N Engl J Med 2004; 350 (6): 586-97. DOI:10.1056/NEJMra030840.

27.- Broliden K, Tolfvenstam T, Norbeck O. Clinical aspects of parvovirus B19 infection. J Intern Med 2006; 260 (4): 285-304. DOI:10.1111/ j.1365-2796.2006.01697.x

28.- Santonja C, Nieto-González G, Santos-Briz Á, de las Nieves Gutiérrez Zufiaurre M, Cerroni L, Kutzner H, et al. Immunohistochemical detection of parvovirus B19 in "Gloves and Socks" papular purpuric syndrome: Direct evidence for viral endothelial involvement. Report of three cases and review of the literature. Am J Dermatopathol 2011; 33 (8): 1. DOI:10.1097/DAD.0b013e318221bc41.

29.- Frühauf J, Massone C, Müllegger RR. Bullous papular-purpuric gloves and socks syndrome in a 42-year-old female: Molecular detection of parvovirus B19 DNA in lesional skin. J Am Acad Dermatol 2009; 60 (4): 691-5. DOI:10.1016/j.jaad.2008.08.037.

30.- Severin M C, Levy Y, Shoenfeld Y. Systemic lupus erythematosus and parvovirus B-19: casual coincidence or causative culprit? Clin Rev Allergy Immunol 2003; 25(1): 41-8. DOI:10.1385/CRIAI:25:1:41.

31.- Aslanidis S, Pyrpasopoulou A, Kontotasios K, Doumas S, Zamboulis C. Parvovirus B19 infection and systemic lupus erythematosus: Activation of an aberrant pathway? Eur J Intern Med 2008; 19 (5): 314-8. DOI:10.1016/j. ejim.2007.09.013.

32.- Sève P, Ferry T, Koenig M, Cathebras P, Rousset H, Broussolle C. Lupus-like presentation of parvovirus B19 infection. Semin Arthritis Rheum 2005; 34 (4): 642-8.
DOI:10.1016/j.semarthrit.2004.07.008.

33.- Pugliese A, Beltramo T, Torre D, Roccatello D. Parvovirus B19 and immune disorders. Cell Biochem Funct 2007; 25 (6): 639-41. DOI:10.1002/cbf.1364.

34.- Murai C, Munakata Y, Takahashi Y, Ishii T, Shibata S, Muryoi T, et al. Rheumatoid arthritis after human parvovirus B19 infection. Ann Rheum Dis 1999; 58 (2): 130-2.

35.- Naciute M, Maciunaite G, Mieliauskaite D, Rugiene R, Zinkeviciene A, Mauricas M, et al. Increased numbers of CD4+CD25+ and CD8+CD25+ T-cells in peripheral blood of patients with rheumatoid arthritis with parvovirus B19 infection. In Vivo 2017; 31 (2): 181-5. DOI:10.21873/invivo.11043.

36.- Naciute M, Mieliauskaite D, Rugiene R, Nikitenkiene R, Jancoriene L, Mauricas M, et al. Frequency and significance of parvovirus B19 infection in patients with rheumatoid arthritis. J Gen Virol 2016; 97 (12): 3302-12. DOI:10.1099/jgv.0.000621.

37.- Sanz-Sánchez T, Daudén E, Moreno de Vega MJ, García-Díez A. Parvovirus B19 primary infection with vasculitis: DNA identification in cutaneous lesions and sera. J Eur Acad Dermatol Venereol 2006; 20 (5): 618-20. DOI:10.1111/j.1468-3083.2006.01502.x.

38.- Meyer O. Parvovirus B19 and autoimmune diseases. Joint Bone Spine 2003; 70 (1): 6-11. DOI:10.1016/S1297-319X(02)00004-0.

39.- Cioc A M, Sedmak D D, Nuovo G J, Dawood M R, Smart G, Magro C M. Parvovirus B19 associated adult Henoch Schönlein purpura. J Cutan Pathol 2002; 29 (10): 602-7. DOI:10.1034/j.1600-0560.2002.291006.x.

40.- Veraldi S, Mancuso R, Rizzitelli G, Gianotti $\mathrm{R}$, Ferrante P. Henoch-Schönlein syndrome associated with human parvovirus B19 primary infection. Eur J Dermatol 9 (3): 232-3.

41.- Ferguson P J, Saulsbury F T, Dowell S F, Török T J, Erdman D D, Anderson L J. Prevalence of human parvovirus B19 infection in children with Henoch-Schönlein purpura. Arthritis Rheum 1996; 39 (5): 880-1. DOI:10.1002/ art.1780370719.

42.- Riavis M, Vonlanthen R, Bianchetti MG. Testing for parvovirus B19 in HenochSchönlein syndrome? Pediatr Dermatol 2009; 15(1): 71. DOI:10.1111/j.1525-1470.1998. tb01279.x.

43.- Corman L, Dolson D. Polyarteritis nodosa and parvovirus B19 infection. Lancet 1992; 339 (8791): 491. DOI:10.1016/01406736(92)91096-Q.

44.- Finkel T H, Leung D Y M, Harbeck R J, Gelfand E W, Török T J, Zaki S R, et al. Chronic parvovirus B19 infection and systemic necrotising vasculitis: opportunistic infection or aetiological agent? Lancet 1994; 343 (8908): 1255-8. DOI:10.1016/S0140-6736(94)92152-0. 45.- Viguier M, Guillevin L, Laroche L. Treatment of parvovirus B19-associated polyarteritis nodosa with intravenous immune globulin. N Engl J Med 2001; 344 (19): 1481-2. DOI:10.1056/NEJM200105103441919.

46.- Sachetto Z, Costa S C, Andrade P D, Conde R A, Amstalden E M, Samara A M, et al. No evidence of parvovirus B19 in tissue samples from patients with polyarteritis nodosa and microscopic polyangiitis as assessed by the polymerase chain reaction. Ann Rheum Dis 2006; 65 (3): 418-20. DOI:10.1136/ ard.2005.040113.

47.- Kiraz S. Parvovirus B19 infection in Behcet's disease. Ann Rheum Dis 2001; 60 (8): 814-5. DOI:10.1136/ard.60.8.814.

48.- Habibagahi M P, Habibagahi Z M, Saidmardani S M M, Sadeghian F M. No definite association between human parvovirus B19 infection and Behcet disease. Iran J Med Sci 2015; 40 (6): 493-500.

49.- Baskan E B, Yilmaz E, Saricaoglu H, Alkan G, Ercan I, Mistik R, et al. Detection of parvovirus B19 DNA in the lesional skin of patients with Behçet's disease. Clin Exp Dermatol. 2007; 32 (2): 186-90. DOI:10.1111/j.13652230.2006.02330.x.

50.- Nikkari S, Mertsola J, Korvenranta H, Vainionpää R, Toivanen P. Wegener's granulomatosis and parvovirus B19 infection. Arthritis Rheum 1994; 37 (11): 1707-8.

51.- Corman L C, Staud R. Association of Wegener's granulomatosis with parvovirus B19 infection: comment on the concise communication by Nikkari et al. Arthritis Rheum 1995; 38 (8): 1174-5.

52.- Eden A, Mahr A, Servant A, Radjef N, Amard $\mathrm{S}$, Mouthon L, et al. Lack of association between B19 or V9 erythrovirus infection and ANCA-positive vasculitides: a case-control study. Rheumatology (Oxford) 2003; 42 (5): 660-4.

53.- Salvarani C, Farnetti E, Casali B, Nicoli D, Wenlan L, Bajocchi G, et al. Detection of parvovirus B19 DNA by polymerase chain reaction in giant cell arteritis: a case-control study. Arthritis Rheum 2002; 46 (11): 3099101. DOI:10.1002/art.10580.

54.- Alvarez-Lafuente R. Human parvovirus B19, varicella zoster virus, and human herpes virus 6 in temporal artery biopsy specimens of patients with giant cell arteritis: analysis with quantitative real time polymerase chain reaction. Ann Rheum Dis 2005; 64 (5): 780-2. DOI:10.1136/ard.2004.025320.

55.- Cooper R J, D’Arcy S, Kirby M, Al-Buhtori M, Rahman MJ, Proctor L, et al. Infection and temporal arteritis: a PCR-based study to detect pathogens in temporal artery biopsy specimens. J Med Virol 2008; 80 (3): 501-5. DOI:10.1002/ jmv.21092.

56.- Gabriel S E, Espy M, Erdman D D, Bjornsson J, Smith T F, Hunder G 
G. The role of parvovirus B19 in the pathogenesis of giant cell arteritis: A preliminary evaluation. Arthritis Rheum 1999; 42( 6): 1255-8. DOI:10.1002/15290131(199906)42:6<1255::AID-

ANR23>3.0.CO;2-P.

57.- Nigro G, Zerbini M, Krzysztofiak A, Gentilomi G, Porcaro MA, Mango T, et al. Active or recent parvovirus B19 infection in children with Kawasaki disease. Lancet (London, England) 1994; 343 (8908) :1260-1. DOI:10.1016/S01406736(94)92154-7.

58.- Bowles N E, Hirono K, Yu X, Ichida F. Absence of parvoviral genomes in endothelial cells of Kawasaki disease patients with coronary artery lesions. Pediatr Infect Dis J 2009; 28 (4): 345. DOI:10.1097/INF.0b013e318199302b.

59.- Zakrzewska K, Corcioli F, Carlsen K M, Giuggioli D, Fanci R, Rinieri A, et al. Human parvovirus B19 (B19V) infection in systemic sclerosis patients. Intervirology. 2009; 52(5): 279-82. DOI:10.1159/000232945.

60.- Ferri C, Zakrzewska K, Longombardo G, Giuggioli D, Storino F A, Pasero G, et al. Parvovirus B19 infection of bone marrow in systemic sclerosis patients. Clin Exp Rheumatol 1999; 17 (6): 718-20.

61.- Magro C M, Nuovo G, Ferri C, Crowson A N, Giuggioli D, Sebastiani M. Parvoviral infection of endothelial cells and stromal fibroblasts: a possible pathogenetic role in scleroderma. $\mathrm{J}$ Cutan Pathol 2004; 31(1): 43-50. DOI:10.1046/ j.0303-6987.2003.0143.x.

62.- Zegpi M S, Ruiz F, Porras N. Pitiriasis liquenoide: presentación de un caso clínico y revisión de la literatura. Rev Chil Pediatría 2015; 86 (2): 121-5. DOI:10.1016/j. rchipe.2015.04.024.

63.- Tomasini D, Tomasini C F, Cerri A, Sangalli G, Palmedo G, Hantschke M, et al. Pityriasis lichenoides: A cytotoxic T-cell-mediated skin disorder. Evidence of human parvovirus B19 DNA in nine cases. J Cutan Pathol 2004; 31 (8): 531-8. DOI:10.1111/j.0303-6987.2004.00186.x.

64.- Kempf W, Kazakov D V, Palmedo G, Fraitag S, Schaerer L, Kutzner H. Pityriasis lichenoides et varioliformis acuta with numerous $\mathrm{CD} 30+$ cells. Am J Surg Pathol 2012; 36 (7): 1021-9. DOI:10.1097/PAS.0b013e31824f4f66.

65.- Nanda A, Alshalfan F, Al-Otaibi M, Al-Sabah H, Rajy J M. Febrile ulceronecrotic MuchaHabermann disease (pityriasis lichenoides et varioliformis acuta fulminans) associated with parvovirus infection. Am J Dermatopathol. 2013; 35(4): 503-6. DOI:10.1097/ DAD.0b013e3182770626.

66.- Crowson A N, Magro C M, Dawood M R. A causal role for parvovirus B19 infection in adult dermatomyositis and other autoimmune syndromes. J Cutan Pathol 2000; 27 (10): 505-15. DOI:10.1034/j.16000560.2000.027010505.x.
67.- Magro C M, Dawood M R, Crowson A N. The cutaneous manifestations of human parvovirus B19 infection. Hum Pathol 2000; 31 (4): 48897. DOI:10.1053/hp.2000.6714.

68.- Mamyrova G, Rider L G, Haagenson L, Wong S, Brown K E. Parvovirus B19 and onset of juvenile dermatomyositis. JAMA. 2005; 294 (17): 2170-1. DOI:10.1001/jama.294.17.2170.

69.- Gelmetti C, Caputo R. Asymmetric periflexural exanthem of childhood: who are you? J Eur Acad Dermatol Venereol 2001; 15 (4): 293-4. DOI:10.1046/j.0926-9959.2001.00298.x.

70.- Guimerá-Martín-Neda F, Fagundo E, Rodríguez F, Cabrera R, Sánchez R, García $\mathrm{M}$, et al. Asymmetric periflexural exanthem of childhood: Report of two cases with parvovirus B19 [1]. J Eur Acad Dermatology Venereol 2006; 20 (4): 461-2. DOI:10.1111/j.14683083.2006.01443.x.

71.- Pauluzzi P, Festini G, Gelmetti C. Asymmetric periflexural exanthem of childhood in an adult patient with parvovirus B19. J Eur Acad Dermatol Venereol 2001; 15 (4): 372-4. DOI:10.1046/j.1468-3083.2001.00291.x.

72.- Harangi F, Várszegi D, Szücs G. Asymmetric periflexural exanthem of childhood and viral examinations. Pediatr Dermatol 1995; 12 (2): 112-5. DOI:10.1111/j.1525-1470.1995. tb00136.x.

73.- Coustou $\mathrm{D}$, Léauté-Labrèze $\mathrm{C}$, BioulacSage P, Labbé L, Taïeb A. Asymmetric periflexural exanthem of childhood: a clinical, pathologic, and epidemiologic prospective study. Arch Dermatol 1999; 135 (7): 799-803. DOI:10.1001/archderm.135.7.799.

74.- Coustou D, Masquelier B, Lafon ME, Labreze C, Roul S, Bioulac-Sage P, et al. Asymmetric periflexural exanthem of childhood: microbiologic case-control study. Pediatr Dermatol 2000; 17 (3): 169-73. DOI:10.1046/ j.1525-1470.2000.01745.x.

75.- Weins A B, Biedermann T, Weiss T, Weiss J M. Wells syndrome. JDDG J der Dtsch Dermatologischen Gesellschaft 2016; 14 (10): 989-93. DOI:10.1111/ddg.13132.

76.- Toulon A, Bourdon-Lanoy E, Hamel D, Fraitag S, Leruez-Ville M, de Prost Y, et al. Wells' syndrome after primoinfection by parvovirus B19 in a child. J Am Acad Dermatol 2007; 56 (2): S50-1. DOI:10.1016/j. jaad.2006.01.058.

77.- Barreiros H, Matos D, Furtado C, Cunha H, Bártolo E. Wells syndrome in a child triggered by parvovirus B19 infection? J Am Acad Dermatol 2012; 67 (4): 166-7. DOI:10.1016/j. jaad.2012.01.012.

78.- Cherng E, McClung A A, Rosenthal H M, Hicks J, Levy M L. Wells' syndrome associated with parvovirus in a 5-year old boy. Pediatr Dermatol 2012; 29 (6): 762-4. DOI:10.1111/ j.1525-1470.2011.01619.x.

79.- Neri I, Bassi A, Patrizi A. Cellulitis-like lesions:
An unusual manifestation of a parvovirus B19 infection. J Pediatr 2016; 175: 239. DOI:10.1016/j.jpeds.2016.05.017.

80.- Villarreal-Villarreal C D, Ocampo-Candiani J, Villarreal-Martínez A. Sweet syndrome: A review and update. Actas Dermosifiliogr 2016; 107 (5): 369-78. DOI:10.1016/j. ad.2015.12.001.

81.- Fortna R, R MD P, Toporcer M, Elder D, E MB C, Junkins-Hopkins J. A case of Sweet syndrome with spleen and lymph node involvement preceded by parvovirus B19 infection, and a review of the literature on extracutaneous Sweet syndrome. Am J Dermatopathol 2010; 32 (6): 621-7. DOI:10.1097/DAD.0b013e3181ce5933.

82.- Gutiérrez-González E, Alvarez-Pérez A, Sánchez-Aguilar D, Toribio J. Sweet's syndrome and acute parvovirus B19 infection. Int J Dermatol 2013; 52 (12): 1611-3. DOI:10.1111/j.1365-4632.2012.05467.x.

83.- Gianotti F. Report on a special case of toxic infection characterized by a desquamative erythemato-infiltrative eruption with lenticular foci and a selective localization at the extremities. Soc Ital Dermatol Sifilogr Sezioni Interprov Soc Ital Dermatol Sifilogr 1955; 96 (6): 678-97.

84.- Boeck K, Mempel M, Schmidt T, Abeck D. Gianotti-Crosti syndrome: clinical, serologic, and therapeutic data from nine children. Cutis 1998; 62 (6): 271-4; quiz 286.

85.- Carrascosa J M, Just M, Ribera M, Ferrándiz C. Papular acrodermatitis of childhood related to poxvirus and parvovirus B19 infection. Cutis 1998; 61 (5): 265-7.

86.- Borreda D, Palomera S, Gilbert B, Lienhardt A, de Lumley L. 24 cases of human parvovirus B19 infection in children. Ann Pediatr (Paris) 1992; 39 (9): 543-9.

87.- Lazzerini P E, Cusi M G, Selvi E, Capecchi M, Moscadelli V, Migliacci N, et al. NonHCV-related cryoglobulinemic vasculitis and parvovirus-B19 infection. Jt Bone Spine. 2018 Jan;85(1):129-130. DOI:10.1016/j. jbspin.2016.12.013.

88.- Terrier B, Marie I, Lacraz A, Belenotti P, Bonnet F, Chiche L, et al. Non HCV-related infectious cryoglobulinemia vasculitis: Results from the French nationwide CryoVas survey and systematic review of the literature. $\mathrm{J}$ Autoimmun 2015; 65: 74-81. DOI:10.1016/j. jaut.2015.08.008.

89.- Chiche L, Grados A, Harlé J, Cacoub P. Mixed cryoglobulinemia: a role for parvovirus B19 infection. Clin Infect Dis 2010; 50 (7): 1074-5. DOI:10.1086/651164.

90.- Gorse A, Boileau J, Goetz J, Stoll-Keller F, Martin T. Parvovirus B19-induced type II mixed cryoglobulinemia. Am J Med 2011; 124 (9): e7-8. DOI:10.1016/j.amjmed.2011.02.039.

91.- Kechaou I, Cherif E, Boukhris I, Azzabi S, 
Kaouech Z. Pseudo-erysipelas: A new atypical cutaneous manifestation of parvovirus B19 primary infection. Med Mal Infect 2016; 46 (2): 107-8. DOI:10.1016/j.medmal.2015.12.002.

92.- Fawaz-Estrup F. Human parvovirus infection: rheumatic manifestations, angioedema, $\mathrm{C} 1$ esterase inhibitor deficiency, ANA positivity, and possible onset of systemic lupus erythematosus. J Rheumatol 1996; 23 (7): 1180-5.

93.- Miyagawa S, Takahashi Y, Nagai A, Yamamoto Y, Nakagawa A, Hori K, et al. Angio-oedema in a neonate with $\mathrm{IgG}$ antibodies to parvovirus B19 following intrauterine parvovirus B19 infection. Br J Dermatol 2000; 143 (2): 428-30. DOI:10.1046/j.1365-2133.2000.03676.x.

94.- Aurelian L, Ono F, Burnett J. Herpes simplex virus (HSV)-associated erythema multiforme (HAEM): a viral disease with an autoimmune component. Dermatol Online J 2003; 9(1): 1.

95.- Sokumbi O, Wetter DA. Clinical features, diagnosis, and treatment of erythema multiforme: a review for the practicing dermatologist. Int J Dermatol 2012; 51 (8): 889-902. DOI:10.1111/j.13654632.2011.05348.x.

96.- Lobkowicz F, Ring J, Schwarz T F, Roggendorf $M$. Erythema multiforme in a patient with acute human parvovirus B19 infection. J Am Acad Dermatol 1989; 20 (5 Pt 1): 849-50. DOI:10.1016/S0190-9622(89)80120-3

97.- García-Tapia A M, Martínez-Rodríguez A, Fernández-Gutiérrez C, Mira J, Lechuga J L. Bullous erythema multiforme caused by human parvovirus B19. Enferm Infecc Microbiol Clin 1993; 11 (10) :575-6.

98.- García-Tapia A M, Fernández-Gutiérrez del Alamo C, Girón J A, Mira J, de la Rubia F, Martínez-Rodríguez A, et al. Spectrum of parvovirus B19 infection: analysis of an outbreak of 43 cases in Cadiz, Spain. Clin Infect Dis 1995; 21 (6): 1424-30.

99.- Xavier S, Forgie S E D. Koplik spots revisited. Can Med Assoc J 2015; 187 (8): 600. DOI: 10.1503/CMAJ.141656.

100.-Bolognia J, Jorizzo J, Schaffer J V. Dermatology. Philadelphia: Elsevier Saunders; 2012. 1348-1349 p.

101.-Annunziato D. Koplik spots and echo 9 virus. N Y State J Med 1987; 87 (12): 667.

102.-Evans L M, Grossman M E, Gregory N. Koplik spots and a purpuric eruption associated with parvovirus B19 infection. J Am Acad Dermatol. 1992; 27 (3): 466-7. DOI:10.1016/S01909622(08)80888-2.

103.-Delbrel X, Sibaud V, Cogrel O, Dianati B, Etienne G, Roux D, et al. Placards pseudocellulitiques multiples et signe de Koplick: une forme originale de primoinfection à parvovirus B19 de l'adulte. Rev Med Interne 2003; 24 (5): 317-9. DOI:10.1016/ S0248-8663(02)00804-4.

104.-Theodoridis A, Konstantinidou A, Makrantonaki E, Zouboulis C C. Malignant and benign forms of atrophic papulosis (KöhlmeierDegos disease): Systemic involvement determines the prognosis. Br J Dermatol 2014; 170(1): 110-5. DOI:10.1111/bjd.12642.

105.-Dyrsen M E, Iwenofu O H, Nuovo G, Magro C M. Parvovirus B19-associated catastrophic endothelialitis with a Degos-like presentation. J Cutan Pathol 2008; 35 (SUPPL. 1): 20-5. DOI:10.1111/j.1600-0560.2007.00974.x

106.-Magro C M, Iwenofu O H, Kearns M J, Nuovo G J, Dyrsen M E, Segal J P. Fulminant and accelerated presentation of dermatomyositis in two previously healthy young adult males: A potential role for endotheliotropic viral infection. J Cutan Pathol 2009; 36 (8): 853-8. DOI:10.1111/j.1600-0560.2008.01171.x.

107.-Fredericks D N, Relman DA. Sequencebased identification of microbial pathogens: a reconsideration of Koch's sequence-based identification of microbial pathogens: a reconsideration of Koch's postulates. Clin Microbiol Rev 1996; 9 (1): 18-33. DOI:10.1098/rspb.1998.0336.

108.-Munakata Y, Saito-Ito T, Kumura-Ishii K, Huang J, Kodera T, Ishii T, et al. Ku80 autoantigen as a cellular coreceptor for human parvovirus B19 infection. Blood 2005; 106 (10): 3449-56. DOI:10.1182/ blood-2005-02-0536.

109.-Wolfromm A, Rodríguez C, Michel M, Habibi A, Audard V, Benayoun E, et al. Spectrum of adult parvovirus B19 infection according to the underlying predisposing condition and proposals for clinical practice. Br J Haematol. 2015; 170 (2): 192-9. DOI:10.1111/bjh.13421

110.-Ballou W R, Reed J L, Noble W, Young N S, Koenig S. Safety and immunogenicity of a recombinant parvovirus B19 vaccine formulated with MF59C.1. J Infect Dis 2003; 187 (4): 675-8. DOI:10.1086/368382.

111.-Bernstein D I, El Sahly H M, Keitel W A, Wolff M, Simone G, Segawa C, et al. Safety and immunogenicity of a candidate parvovirus B19 vaccine. Vaccine 2011; 29 (43): 7357-63. DOI:10.1016/j.vaccine.2011.07.080.

112.-Servey J T, Reamy B V, Hodge J. Clinical presentations of parvovirus B19 infection. Am Fam Physician 2007; 75 (3): 373-6.

113.-Bachmeyer C, Fédida B, Maisonobe T, Abbara S, Lecadet A, Georgin-Lavialle S. Limb weakness and pain in a patient with primary Sjögren syndrome. Neth J Med 2016; 74 (9): 414. 